\title{
Strong Structuration Theory in Accounting Research
}

\author{
Alan Coad, Lisa Jack and Ahmed Kholeif
}

\begin{abstract}
Purpose - The purpose of this paper is to discuss the interdisciplinary use of strong structuration theory and consider the impact of this for accounting research. The paper also provides an overview of the contributions advanced by the other papers in this special issue of Accounting, Auditing and Accountability (AAAJ).
\end{abstract}

Design/methodology/approach - This paper draws together and identifies key issues and themes related to the rapidly-evolving interdisciplinary use of strong structuration theory and considers the relevance of these issues to accounting research.

Findings - The paper highlights that there is a growing use of strong structuration theory in a number of disciplines, such as in healthcare, learning studies, management, migration studies and childcare as well as in accounting. Within the accounting discipline, whilst the interest began in management accounting and control, there are on-going studies of the not for profit sector, social and environmental accounting, financial reporting standards and audit. Using strong structuration theory, researchers are more interested in the people (individually or collectively) and their analysis of their conduct and context. They are moving forwards from an overly static use of the quadripartite framework to a more dynamic approach that also includes the other important central elements of strong structuration that focus on the issue of agency in situ rather than on structure cut off from agency.

Research limitations/implications - The paper provides important insights into emerging iss ues and developments in strong structuration theory that have clear relevance to accounting research and practice as well as other disciplines.

Originality/value - This paper, and other contributions to this special issue of $A A A J$, provide a basis and a research agenda for accounting scholars seeking to undertake empirical research using Stones' strong structuration theory.

Keywords - Strong Structuration Theory, Accounting, Position-practice relations, Agents-in-focus, Quadripartite framework, Conduct Analysis, Context Analysis

Paper type - Research Paper

Acknowledgements

The authors wish to thank James Guthrie for his practical support and intellectual encouragement in developing this AAAJ special issue and for arranging the review of this paper, as well as those who contributed by submitting papers and acting as reviewers. The authors would also like to thank Professor Danture Wickramasinghe and the University of Glasgow, and Professor Frédéric Gautier and IAE de Paris for hosting the workshops that contributed to the development of papers in the special issue and in the further development of the network of researchers applying strong structuration theory in the accounting and management disciplines. 


\section{Introduction - strong structuration theory}

In 2005 the sociologist Rob Stones published what has been described as the most important development of structuration theory since Giddens himself turned to other matters (Bryant and Jary, 2011). Now widely called Strong Structuration Theory, it moves away from the relatively abstract ontology in which Giddens was interested, and encourages researchers to explore empirical case studies of particular agents and structures, where individual agents are situated in a web of position-practice relations.

Whilst the duality of structure remains its defining construct, Stones asserts that the duality is best understood through analysis of a quadripartite framework of interrelated components, comprising external structures, internal structures, active agency and outcomes. This framework represents an ontologically distinct version of structuration theory, where Stones gives greater prominence to spatial relations and how different actors interact with one another; and, by means of identifying a sliding scale of ontological abstraction, offers the potential for multi-layered studies of sociological phenomena. Stones also strengthens structuration theory by paying much more explicit attention than Giddens to issues of epistemology and methodology.

For Stones (Stones and Jack, 2016), strong structuration is a conceptual methodology that provides a bridge between theory and empirical research. Researchers are actively encouraged to design research projects using theory as a starting point and to work with real data to develop new theoretical ideas. Stones (2005) sees his work not as a framework for conceptual analysis but as a basis for the imaginative working out of concepts and empirical data that in turn builds new theoretical ideas.

\section{Strong structuration theory as a tool for an interdisciplinary dialogue}

A growing number of scholars, particularly early career researchers, across several disciplines are working with strong structuration theory, following the work of Stones (2005). We are aware of studies in healthcare, learning studies, management, migration studies, biotechnology, and childcare as well as accounting. Within the accounting discipline, whilst the interest began in management accounting and control, there are on-going studies of the not for profit sector, social and environmental accounting, financial reporting standards and audit. Stones himself was initially astounded by this interest, but as he says in this issue (Stones and Jack, 2016, p.X) 'a lot of the meso-level spatial dimension and sense of organisations has migrated to business schools and management schools, and a lot of sociologists have migrated as well, and you don't now find much of this dimension in sociology departments.....' $\mathrm{He}$ also sees that investigating 'the status and the adequacy of knowledge is probably more important for the sort of world you're in than it is for many of today's sociologists'.

Within the accounting and management disciplines, there is a growing network of interested scholars who are meeting and developing our collective understanding not just of the theory but of how we can bridge theory and empirical research. There have been two workshops in the last two years (in Glasgow and Paris) in which researchers are moving beyond the framework offered by the quadripartite nature of structuration to also include the important central elements of strong structuration which focus on the issue of agency embedded in structures rather than on structure cut off from agency (Englund and Gerdin, 2014). It is interdisciplinary work in progress, and this special issue allows us to bring some of the ongoing empirical work forward to 
contribute towards continuing discussions and debates around interpretative research in accounting (for example, Elharidy et al., 2008; Durocher, 2009). The issue also allows us space to engage in an interdisciplinary dialogue with a contemporary social theorist.

This is really where empirical work in accounting could not only inform the development of the theory but also use the theory as a springboard for new social theory emerging from close observation of how accounting shapes societal relationships. It is a concern with the concept of agency - its active dimension interlacing with internalised structures - rather than with a conception of structures looked at just from the outside, that drives strong structuration theory. This is what makes it different from Giddens' version. Englund and Gerdin $(2014$, p.) note that little work is done using the strategic conduct analysis outlined Giddens' (1984). In accounting studies, more emphasis is placed on the institutional analysis of structure and the outputs of accounting - its systems and its reports. Using Stones' version, we are more interested in the people (individually or collectively) and their analysis of their conduct and context. In other words, we look at the status and adequacy of knowledge on which people act. It is this kind of investigation that is mobilised using strong structuration theory in accounting research.

Rather than systems, we ask how people - the agents-in-focus- perceive and understand the constraints and possibilities that surround them. It is the double hermeneutic of which Giddens spoke - our understanding of how others understand their situation. Such analysis is concerned with how they draw on that knowledge of internal and external structures when making decisions, choosing which arguments and which words/figures/calculations to use, communicating with others, resisting and bringing about change. The active verbs are important, because the analysis does not focus on the decision made or the report written or the accounting method used but on the continual production, re-production and moments of doing otherwise that happen. In other words, we should be interested in the study of the process of how structure at Time 1 changes (or doesn't change) into a different structure at Time 2, rather than the study of two structures at two different points in time. Stones says, strong structuration lends itself to the 'deft and careful brushstrokes of an artist intent on capturing the details of her subject' (2005, p.127). In case study work and in accounting, the dynamic analysis of who said what to who, why, where and when with what consequences for social relationships at micro-, meso- and macrorelationships provides the starting point for research design. It requires curiosity about the craft of accounting and an interest in accountants, managers and users as people that Hopwood (2009) lamented was missing from much accounting research.

What we have here is not just an argument about method or domain theory (Lukka and Vinnari, 2014), it is about also building social theory from the understanding of why people use accounting to control and change others, and the effects of the choices of communication they make. Using strong structuration theory, at least as an initial conceptual methodology, should allow us to wrangle with such questions. It builds on critical accounting and interpretative studies by moving onwards from putting accounting in its social and organisational context towards an understanding of society through an analysis of the ways in which accounting is actively constructed and communicated. Jack $(2016 ; 2013)$ has formulated this revised approach to accounting and social theory as the study of the use, misuse and abuse of accounting 
communications by people in ways that affect relationships in society, and elements of this approach can be seen in the papers in this issue.

\section{An overview of the papers in the $A A A J$ special issue}

The papers in this AAAJ issue go some way toward moving beyond an overly static use of the quadripartite framework of structuration towards focusing on the processual flow of agents actively engaging with their structural context, and applying agent's conduct analysis and agent's context analysis to this end.

Makrygiannikis and Jack (2016) use strong structuration theory to study aspects of management accounting change in a Greek hospitality organisation in response to the financial crisis of 2008. A retrospective field study was designed to examine the specificities of how, why, when, and by whom changes in budgeting and control practices took place over a period of several years. The theoretical lens adopted demonstrates how change is endogenously created even if triggered by broader contextual factors. It is a perspective that places greater emphasis on the perceptions and conduct of agents when compared with institutional accounts of change. An early response to the financial crisis was for senior management to press for more consistent application of the existing norms of budgeting practices. Later, agents involved in budgeting and control at various levels of the organisation came to criticise and modify existing norms. The changes resulted in quite sophisticated use of budgetary control, where variance management and budget revisions became proactive rather than reactive.

Methodologically, we see how strong structuration theory overcomes the limitations of Giddens' prescriptions for research, which tend to produce accounts of structuration processes that are either overly deterministic or overly voluntaristic. Stones (2005) offers an alternative approach which provides an emphasis on epistemology rather than ontology. This is based on agent's conduct analysis and agent's context analysis, which produces a far more nuanced account of structuration processes in which the agent(s)-in-focus and their perceptions of structure, are the basis of active agency. In the case study we observe variations in the ways agents draw upon structures, unreflectively or critically, and how they act to reproduce or change structures, routinely or strategically. Such perceptions and actions are local, and it is these changes in conduct and context which are significant in understanding management accounting change.

Similar themes are evident in the paper by Feeney and Pierce (2016), which deploys strong structuration theory to examine the role of accounting information in New Product Development (NPD). It aims to improve our understanding of the connecting tissue between different elements of Stones' (2005) quadripartite model and also develops aspects of the processes of structuration arising out of its web-like nature. In this paper, formal and informal accounting information are conceptualised as external structures over which agents have differing degrees of control. Managers in different parts of the same organisation respond differently to accounting information, and we see their use of this information derives as much from their own dispositions and conjuncturally-specific internal structures as it does from the objective characteristics of the structures with which they interact. 
In this way, strong structuration theory helps us establish the link between accounting information and the individuals using it, whilst at the same time recognising how those individuals are themselves affected by their contextual circumstances. Feeney and Pierce's (2016) deployment of a composite research strategy also illustrates the interacting and overlapping nature of internal and external structures when examining a number of agents within a given conjuncture. Not only do we observe how the contrasting phenomenology of different participants in NPD affect their use of accounting information, but also how their resulting behaviour goes on to influence the dispositional frames of others. Furthermore, the study illustrates how conflicts between agents' dispositions and their conjuncturally-specific internal structures also affect their attitudes towards and their use of accounting information in NPD.

Harris, Northcott, Elmassri and Huikku (2016) respond to recent calls to use case studies as a basis for theorisation, by proposing strong structuration theory as a basis for developing a domain theory of strategic investment decision making (SIDM) processes. Research on such processes has been dominated by quantitative and functionalist studies of capital budgeting and investment appraisal, with relatively few field studies examining the lived experiences of decision makers in real organisational settings. Harris et al (2016) initially conduct a wide-ranging literature review to examine how SIDM case studies have previously been theorised, concluding that a key factor inhibiting cumulative knowledge-building and theorisation is the absence of a consistent conceptual framework. Prior studies have used grounded theory, personal construct theory, actor network theory and practice theory; whilst others make no explicit statement about theorisation.

To further their proposal, Harris et al (2016) reanalyse four published case studies, one from each of the previously-used theoretical perspectives, so as to illustrate how strong structuration theory provides an appropriate lens for addressing the research questions posed in SIDM studies; to demonstrate its potential to offer additional insights to SIDM research; and to identify key methodological issues in using this approach to enhance our understanding of SIDM processes and practices. The authors conclude that strong structuration theory holds greater promise for a domain theory of SIDM than either grounded theory or practice theory, as it guides the researcher to unpicking the complex social processes of human interaction. They suggest there might be a role for personal construct theory in teasing out agents' internal structures within a strong structuration study, but that personal construct theory cannot fulfil the function of a domain theory because it reveals insufficient evidence about power asymmetries and forms of resistance in position-practice relations. And, whilst they acknowledge many of the benefits of actor-network theory, they argue it sheds insufficient light on agents' knowledgeability, institutional effects and the dynamics of action in networks. Overall, they conclude that strong structuration theory is better suited than the alternatives to study SIDM.

Finally, Moore and McPhail (2016) draw on the concept of position-practices at the macro, meso and micro levels of ontology of strong structuration theory in order to understand how a carbon pricing system was developed whilst recognising legitimate uncertainty in carbon measurement science as well as the role of trust in climate science, policies and markets. At the macro (policy) level, documentary evidence was used to analyse carbon accounting policy development. At the meso (industry) and micro (organizational) levels, a longitudinal case study of the Victorian water industry 
in Australia was conducted to collect qualitative interviews and other evidence to examine the nature of active agency within a field of position-practice relations that led to the development of carbon accounting frameworks.

The development of carbon accounting frameworks at both the meso and ontic levels was enabled by the conjuncturally-specific knowledge of networked agents within a field of position-practice relations. Furthermore, the active agency of those in less influential positions at the micro level sought to shape the outcomes of those in more powerful positions at the macro and meso levels as they had to reassess their conjuncturally-specific knowledge of the situation and to modify their use of soft power and persuasive communication. The use of strong structuration theory incorporating the use of soft power and persuasive communication, as illustrated in this study, enables accounting researchers to investigate deeply the communications, actions and power relations which accountants, managers and other professionals choose to use when embedding practices. Such practices are shaped at different ontological levels not necessarily from coercive external pressures but from the interplay of different structuration processes over time and space.

\section{Conclusion}

Stones' strong structuration theory becomes a tool for an interdisciplinary dialogue and is used by a growing number of scholars in various disciplines as well as accounting. Within the accounting discipline, whilst the interest began in management accounting and control, there are on-going studies of the not-for-profit sector emerging economies, financial reporting standards and audit. Initially, there is a tendency for early career researchers simply to classify data under the quadripartite model but researchers are now moving away from this use of the framework (following Coad and Herbert, 2009; Coad and Glyptis, 2014 and Stones, 2005; 2015 in particular) to focus instead on the issue of active agency embedded in ongoing structural relations, as well as understanding the application of agent's conduct analysis and agent's context analysis. The papers in this AAAJ special issue reflect this continuing development in the use of strong structuration theory.

\section{References}

Bryant, C.G.A., \& Jary, D., (2011), Anthony Giddens, in Ritzer, G., Stepnisky, J. (Eds.) The Wiley-Blackwell companion to major social theorists, Wiley-Blackwell, Malden.

Coad, A.F., \& Herbert, I.P., (2009), Back to the future: new potential for structuration theory in management accounting research? Management Accounting Research, Vol 20, pp.177-192.

Coad, A.F., \& Glyptis, L.G., (2014), Structuration: a position-practice perspective and an illustrative study. Critical Perspectives on Accounting Vol. 25, pp.142-161.

Durocher, S. (2009). The future of interpretive accounting research: The contribution of McCracken's (1988) approach, Qualitative Research in Accounting \& Management Vol. 6 No. 3, pp.137 - 159.

Elharidy, A., Nicholson, B. and Scapens, R. (2008), Using grounded theory in interpretive management accounting research. Qualitative Research in Accounting \& Management, Vol. 5 No. 2, pp.139 - 155.

Englund, H. and Gerdin, J. (2014), Structuration Theory in Accounting Research: Applications and accountability. Critical Perspectives on Accounting, Vol. 25 No. 2, pp.162-180. 
Feeney, O. and Peirce, B. (2016), Strong structuration theory and accounting information: an empirical study, Accounting, Auditing and Accountability Journal, Harris, E., Elmassri, M., Northcott, D. and Huikku, J. (2016), Theorising Strategic Investment Decision-Making using Strong Structuration Theory, Accounting, Auditing and Accountability Journal,

Hopwood, A. (2009), Reflections and projections - and many, many thanks. Accounting, Organizations and Society, Vol. 34 No. 8, pp.887-894.

Jack, L. (2016), Accounting and social theory: an introduction, Routledge, Abingdon. Jack, L. (2013), Accounting communications inside organisations, in Jack, L., Davidson, J. and Craig, R., Editors, (2013), The Routledge Companion to Accounting Communication, Routledge, Abingdon.

Lukka, K. and Vinnari, E. (2014), Domain theory and method theory in management accounting research, Accounting, Auditing \& Accountability Journal, Vol. 27 No. 8, pp.1308-1338.

Makrygiannikis, G. and Jack, L. (2016), Understanding management accounting change using strong structuration frameworks, Accounting, Auditing and Accountability Journal, Moore, D. and McPhail, K. (2016), Strong structuration and carbon accounting: A position-practice perspective of policy development at the macro, industry and organizational levels, Accounting, Auditing and Accountability Journal,Stones, R. (2015), Why current affairs needs social theory, Palgrave Macmillan: Basingstoke. Stones, R. (2005), Structuration theory, Palgrave Macmillan, Basingstoke.

Stones, R. and Jack, L. (2016) The bridge between ontological concepts and empirical evidence: an interview with Rob Stones, Accounting, Auditing and Accountability Journal, 